\title{
EVALUATION OF NATURAL RADIOACTIVITY IN SOME ALBANIAN BOTTLED WATER SAMPLES
}

\author{
Iris Bakiri ${ }^{1^{*}}$ \\ I*University of Tirana, Institute of Applied Nuclear Physics, Tirana, Albania; \\ *Corresponding Author Iris Bakiri, e-mail: iris.bakiri@unitir.edu.al;
}

Received February 2021; Accepted March 2021; Published June 2021;

DOI: https://doi.org/10.31407/ijees11.337

\begin{abstract}
According to the Council Directives 98/83/ EC, "On the quality of water intended for human consumption" and later by DCM no. 379, On the approval of the regulation "Quality of drinking water", which dates on May 25, 2016, the total concentration of the gross alpha activity in drinking water is limited to $0.1 \mathrm{~Bq} /$ litre and for gross beta activity concentration at $1 \mathrm{~Bq} /$ litre. Gross alpha activity concentration includes all alpha emitters, except for radon, while gross beta activity concentration includes all beta-emitters, except for tritium and potassium-40. The work presented in this paper is about the use of technique of liquid scintillators as an alternative technique in the determination of the natural radioactivity of some bottled water available at the Albanian market. The standard procedure for determining the overall alpha and beta activity is through proportional counters. The ability of liquid scintillators to perform alpha and beta discrimination provides the possibility of using an alternative method to that traditional approach. The measurements were performed by using the Tri-Carb 3170 TR / SL type Perkin Elmer liquid scintillator counter, capable of performing alpha / beta discrimination. The natural radioactivity values of nine bottled water samples for gross alpha activity ranges from $0.004074311 \pm 0.002002 \mathrm{~Bq} / \mathrm{L}$ to $0.07192243 \pm 0.002888$ $\mathrm{Bq} / \mathrm{L}$ and for gross beta activity range from $0.068518986 \pm 0.002002 \mathrm{~Bq} / \mathrm{L}$ to $0.159877634 \pm 0.003904 \mathrm{~Bq} / \mathrm{L}$. These values are much lower than the sanitary standards provided by the Albanian law.
\end{abstract}

Keywords: natural radioactivity, $\alpha$-radioactivity, $\beta$-radioactivity, bottled water. 